\title{
Identificación y aprovisionamiento de ftanita o chert en la cuenca superior del Arroyo Tapalqué (Olavarría, provincia de Buenos Aires, Argentina)
}

María Paula Barros ${ }^{1}$ y Pablo Gerónimo Messineo ${ }^{2}$

\section{RESUMEN}

Un alto porcentaje de los artefactos líticos que han sido recuperados en los sitios arqueológicos de la cuenca superior del Arroyo Tapalqué (Olavarría, Buenos Aires, Argentina) han sido confeccionados sobre ftanita o chert. Esta materia prima aparece en tres niveles estratigráficos dentro de la secuencia sedimentaria Precámbrical Paleozoica inferior de las Sierras Bayas de Olavarría. En este trabajo se analizan las características litológicas de los diferentes niveles mediante difracción de Rayos $X$ y se los compara con los resultados obtenidos de las muestras de los sitios arqueológicos superficiales Laguna La Barrancosa-2, Laguna Blanca Chica, Cerro Núcleo Central-1 y Arroyo Tapalqué. Los resultados obtenidos indican que los grupos humanos que habitaron la cuenca superior del Arroyo Tapalqué durante el Holoceno Tardio se habrían aprovisionado del segundo nivel de ftanita o chert.

Palabras claves: difracción de Rayos X - aprovisionamiento y distribución de ftanita - región pampeana.

\section{ABSTRACT}

A significant percentage of lithic artifacts recovered from archaeological sites located in the upper section of the Tapalqué river basin (Olavarría District, Buenos Aires province, Argentina) are made of chert or ftanita. This raw material has been found in three different stratig raphic levels in the lower Precambrian/Palaeozoic sedimentary sequence of Sierras Bayas, Olavarría. In this paper each chert level is characterised using $X$-ray diffraction and results are compared with samples from surface archaeological sites (Laguna La Barrancosa-2, Laguna Blanca Chica, Cerro Núcleo Central-1 and Arroyo Tapalqué). It is proposed that

CONICET - Investigaciones Arqueológicas y Paleontológicas del Cuaternario Pampeano (INCUAPA), Facultad de Ciencias Sociales, Universidad Nacional del Centro de la Provincia de Buenos Aires. Av. Del Valle 5737, Olavarría (B7400JWI), ARGENTINA. Email: pbarros@ soc.unicen.edu.ar mapaulabarros@hotmail.com

2 CONICET - Investigaciones Arqueológicas y Paleontológicas del Cuaternario (INCUAPA), Facultad de Ciencias Sociales, Universidad Nacional del Centro de la Provincia de Buenos Aires, Av. Del Valle 5737, Olavarría (B7400JWI), ARGENTINA. Email: pmessine@ soc.unicen.edu.ar pablogmessineo@hotmail.com human groups which inhabited the upper section of the Arroyo Tapalqué river basin during the Late Holocene exploited the second level of chert or ftanita.

Key words: X-Ray diffraction - chert acquisition and distribution - pampean region.

Recibido: abril 2004. Manuscrito revisado aceptado: septiembre 2004.

\section{Introducción}

Una de las líneas de investigación que ha cobrado relevancia en las últimas décadas es el estudio sobre abastecimiento, explotación y uso de las materias primas líticas. A partir del análisis de los materiales líticos provenientes de diferentes sitios arqueológicos que se encuentran ubicados en la región pampeana, se evidencia la utilización de diferentes tipos de rocas. Una de las materias primas más explotadas regionalmente y que presenta estudios detallados sobre su utilización en la región es la ortocuarcita superior de la Formación Sierras Bayas (Flegenheimer et al. 1996; Bayón et al. 1999; Flegenheimer y Bayón 2002, entre otros). En tanto que otras rocas, como por ejemplo la ftanita o chert $^{3}$, han sido consideradas secundarias y, según su explotación, de forma mayoritariamente local y, en menor medida, de forma areal y regional (Lozano 1991; Flegenheimer y Bayón 2002).

Según Lozano (1991), la ftanita presenta tres aspectos relevantes en cuanto a su utilización en la región: 1) su condición alóctona en la mayoría de los sitios; 2) su gran dispersión espacial, que ex-

\footnotetext{
Los términos ftanita y chert son utilizados como sinónimos en este trabajo y representan un término general para identificar a las rocas sedimentarias silíceas microcristalinas. Un "tipo" de ftanita o chert se refiere a un recurso conocido (p.e., un tipo específico de ftanita o chert) que se relaciona a una formación geológica espacialmente restringida (p.e., la ftanita o chert de las Sierras Bayas de Olavarría).
} 
cede las áreas serrana e interserrana; y 3) ocupa el segundo lugar, después de las cuarcitas, en las preferencias de materias primas líticas de los grupos humanos bonaerenses. Estas características, según este autor, se relacionarían con un tipo de tecnología en donde los artefactos confeccionados sobre esta materia prima en general serían conservados.

Sin embargo, a partir de las investigaciones realizadas en el sector de la cuenca superior del Arroyo Tapalqué (partidos de Olavarría y Benito
Juárez, provincia de Buenos Aires) (Figura 1), se observa un predominio de la ftanita en los contextos líticos provenientes de los sitios arqueológicos superficiales y una estrategia tecnológica diferente de la propuesta por Lozano (1991), que se evidencia en la presencia de altos porcentajes de instrumentos informales (Messineo 2002; Messineo y D'Augerot 2004). Por otro lado, investigaciones desarrolladas en los partidos de Bolívar, Tapalqué y Lamadrid (ubicados en sectores próximos a la cuenca superior del Arroyo Tapalqué) permiten observar que un alto porcen-

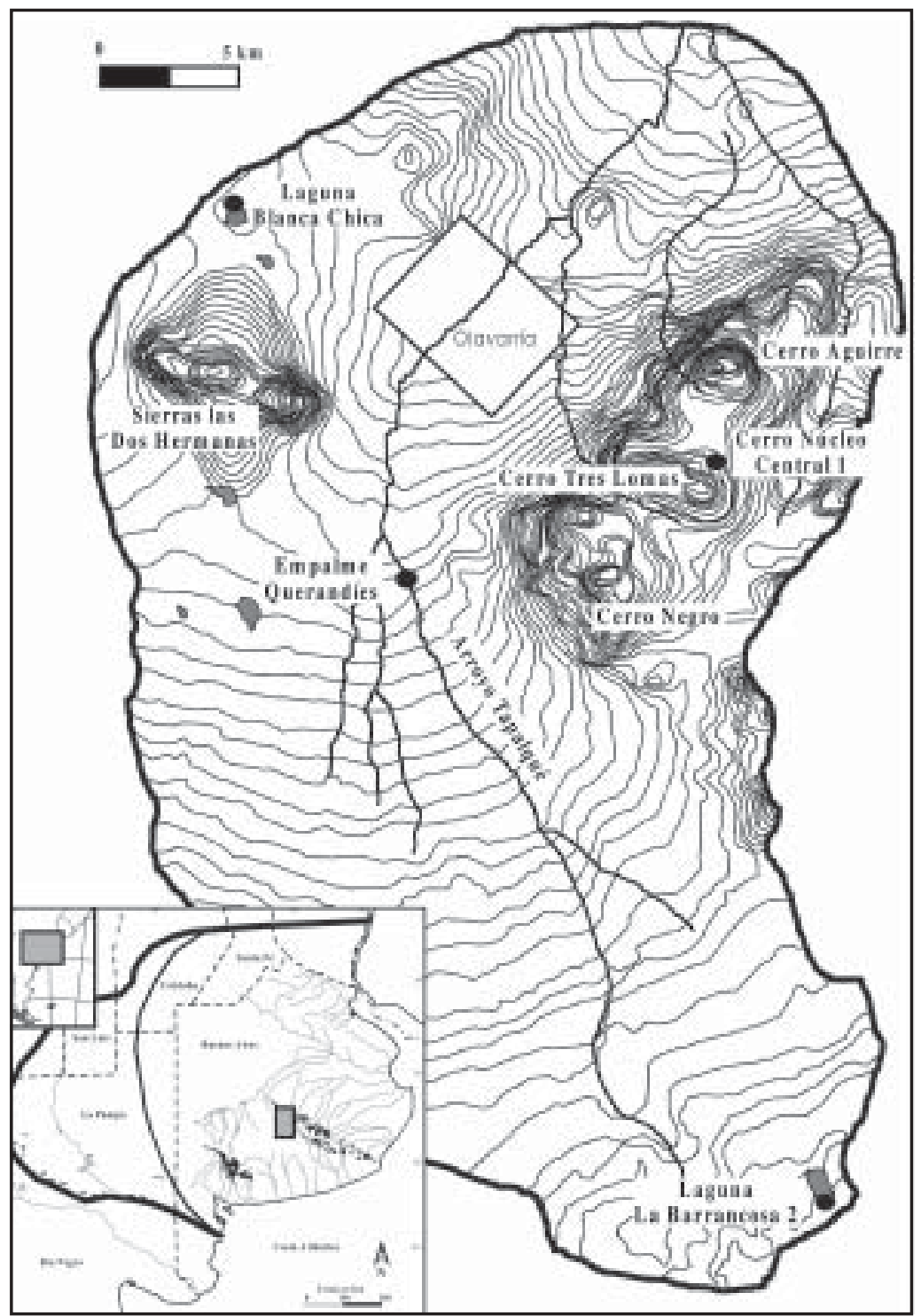

Figura 1. Ubicación de la cuenca superior del Arroyo Tapalqué en la provincia de Buenos Aires y de los sitios considerados en el trabajo. 
taje de los materiales líticos recuperados en los sitios arqueológicos fueron elaborados sobre ftanita (Bórmida 1960, s/f; Crivelli Montero et al. 1990/92, 1997).

Otras investigaciones desarrolladas en la región también han focalizado sus estudios sobre la localización y caracterización de los afloramientos primarios y secundarios de las materias primas líticas que fueron utilizadas por los grupos en el pasado. Dichas investigaciones han detectado canteras y talleres arqueológicos evidenciando la explotación de distintas rocas: ortocuarcitas, metacuarcitas, chert síliceo, ftanita, riolitas, rodados patagónicos, dolomías silicificadas, entre otras (Lozano 1991; Flegenheimer 1991; Berón et al. 1995; Pupio 1996; Flegenheimer et al. 1996, 1999; Bayón y Zavala 1997; Oliva y Moirano 1997; Ormazábal 1999; Messineo 2002).

Con respecto a la ftanita, Lozano (1991) describe una cantera-taller de esta materia prima en el Cerro Aguirre, ubicada en las Sierras Bayas (partido de Olavarría). También fueron detectadas canteras en el Arroyo Diamante (partido de Barker) y canteras potenciales en el Cerro El Sombrero (partido de Lobería) (Barna y Kain 1994; Flegenheimer et al. 1996). Por otro lado, las investigaciones desarrolladas permitieron detectar la presencia de otras canteras-taller, canteras potenciales y talleres de ftanita ubicados en distintos cerros de las Sierras Bayas (Cerro Tres Lomas, Cerro Largo y Cerro Núcleo Central-1) (Messineo 2001, 2002) (Figura 2).

Geológicamente la ftanita o chert ha sido reconocida por lo menos en tres niveles estratigráficos dentro de la secuencia sedimentaria Precámbrica/ Paleozoica inferior de las Sierras Bayas de Olavarría, siendo el segundo nivel el que se ubica en la base de la Formación Cerro Largo, el que aflora en las laderas de los cerros (Poiré 1987, 1993). Sobre la base de los estudios petrográfico y de difracción de Rayos X se pudo determinar que las muestras que pertenecían al segundo nivel de ftanita eran diferentes a las del tercer nivel en la composición mineralógica y en la estructura interna de la roca (Messineo et al. 2004).

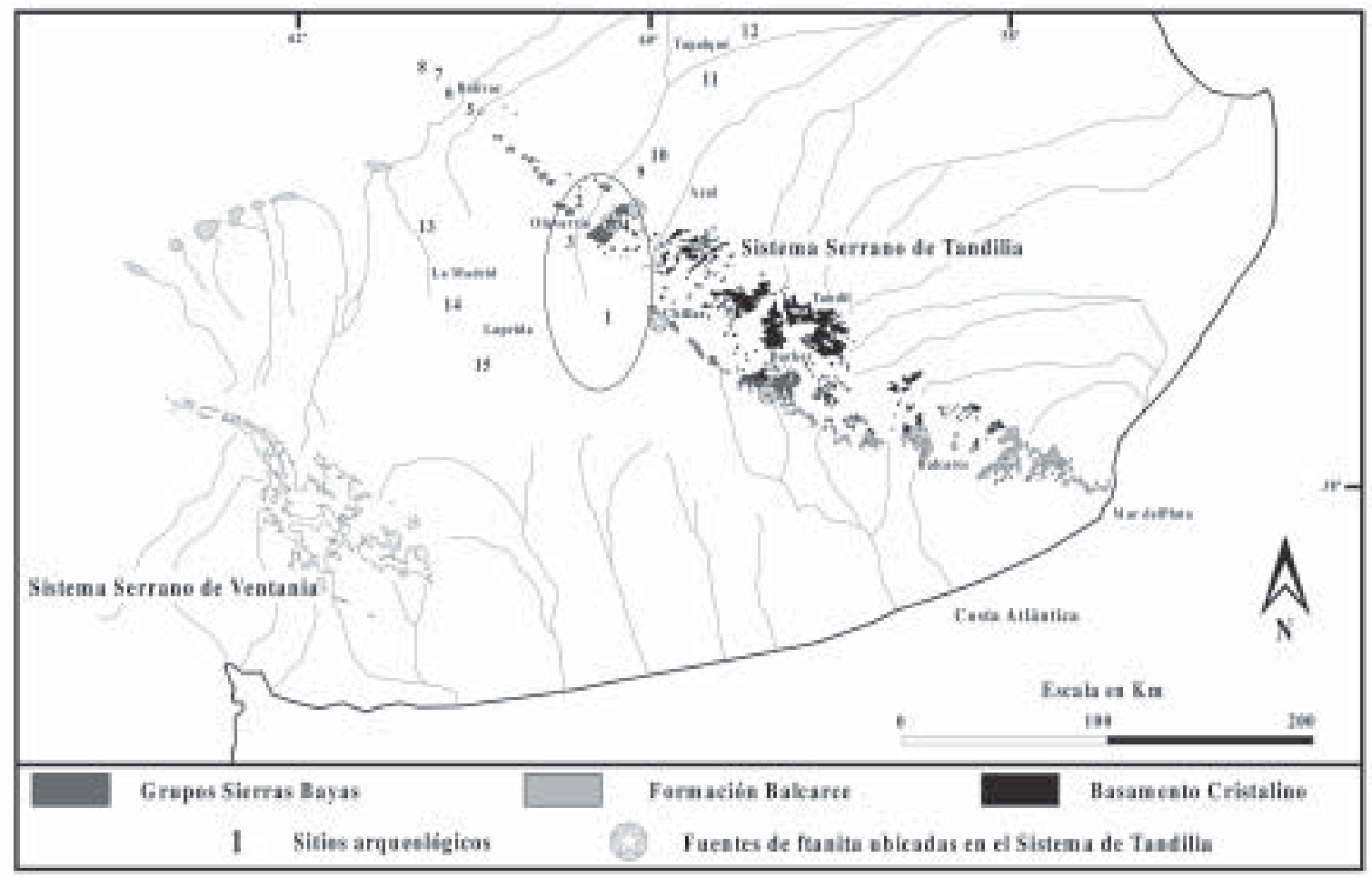

Figura 2. Ubicación de las fuentes de ftanita o chert en el Sistema Serrano de Tandilia y de los sitios arqueológicos que presentan altos porcentajes de la misma. Referencias: 1) Laguna La Barrancosa-2; 2) Laguna Blanca Chica; 3) Empalme Querandíes; 4) Cerro Núcleo Central-1; 5) Laguna Blanca Grande; 6) Laguna Cabeza de Buey; 7) Laguna Cubiló; 8) Laguna El Recado; 9) Laguna de Frías; 10) Laguna de Burgos; 11) Laguna de Medina; 12) Laguna Pluma Augero; 13) Escuela Agropecuaria; 14) Fortín Necochea; 15) Laguna del Tropa. 
En este sentido, uno de los objetivos de este trabajo es determinar cuál de los tres niveles de ftanita identificados en las Sierras Bayas fueron explotados por los grupos en el pasado. Con tal fin se seleccionaron artefactos líticos confeccionados sobre ftanita provenientes de cuatro sitios arqueológicos ubicados en la cuenca superior del Arroyo Tapalqué (Laguna La Barrancosa-2, Laguna Blanca Chica, Cerro Núcleo Central-1 y Arroyo Tapalqué), y se realizaron estudios mineralógicos utilizando difracción de Rayos X para compararlos con los resultados obtenidos de los difractogramas de los niveles de ftanita de las Sierras Bayas.

Otro objetivo es discernir cuáles fueron los factores que incidieron en las estrategias de obtención y explotación de la ftanita por parte de las sociedades cazadoras recolectoras que habitaron la cuenca superior del Arroyo Tapalqué y sectores próximos a la misma. Con tal fin se establecerá cuál es la representación de las distintas materias primas en los sitios arqueológicos analizados y se calcularán las distancias de los sitios a las fuentes de ftanita (p.e., canteras y talleres).

\section{Area de estudio}

La cuenca superior del Arroyo Tapalqué (partido de Olavarría, provincia de Buenos Aires) se encuentra ubicada en el sector noroeste de la región que Nágera (1940) denominara Tandilia o, como se la conoce actualmente, Sierras Septentrionales de la provincia de Buenos Aires (Harrington 1956; Fidalgo et al. 1986). Es importante destacar que la cuenca se extiende sobre dos áreas de la región pampeana. Por un lado, se localiza en la parte noroccidental del área interserrana y, por el otro, en el sector occidental del sistema serrano de Tandilia. Sus límites norte (entre las ciudades de Olavarría y Azul) y sur (Laguna La Barrancosa) son los paralelos $36^{\circ} 48^{\prime} 30^{\prime \prime}$ y $37^{\circ} 25^{\prime} 30^{\prime \prime}$ de Latitud Sur, respectivamente. Al este (divisorias de aguas con la cuenca del Arroyo Azul) y al oeste (Laguna Blanca Chica, La Tigra y las Sierras de las Dos Hermanas) el área se encuentra delimitada por los meridianos de $60^{\circ} 05^{\prime} 10^{\prime \prime}$ y $60^{\circ} 30^{\prime}$ 56" Longitud Oeste. El área cubre aproximadamente $2000 \mathrm{~km}^{2}$ (ver Figura 1).

Dentro de la cuenca se registran dos zonas claramente diferentes. La primera corresponde a las estribaciones occidentales del cordón serrano de
Tandilia y se caracteriza por la presencia de cerros bajos y de suaves lomadas denominadas Sierras o Serranías de Olavarría. La segunda zona se caracteriza por suaves ondulaciones que acompañan las líneas de drenaje. La red hidrográfica se encuentra escasamente desarrollada, siendo el Arroy o Tapalqué el colector principal. Existen muy pocos cursos tributarios dentro de la zona de estudio, siendo el más importante el Arroyo San Jacinto (Fidalgo et al. 1986).

Las investigaciones geológicas, principalmente en las estribaciones occidentales del cordón serrano de Tandilia (Sierras Bayas), señalan la presencia de ortocuarcitas superiores de la Formación Sierras Bayas (Iñíguez et al. 1996) y de ftanita o chert (Iñíguez et al. 1989; Poiré e Iñíguez 1984). Estos datos son importantes porque estas rocas sirvieron como materias primas líticas y fueron empleadas en la confección de instrumentos en toda la región pampeana.

Aunque en el área de estudio y aledañas ambas materias primas están presentes (Iñíguez et al. 1989), hasta la actualidad no se conocen canteras arqueológicas de cuarcita. En cambio, con las ftanitas (chert) existen más datos arqueológicos, tales como el registro de canteras-taller (p.e., Cerro Aguirre y Cerro Tres Lomas), talleres y canteras potenciales que sugieren que esta materia prima fue un recurso importante en el área (Lozano 1991; Messineo 2002).

En la cuenca superior del Arroyo Tapalqué, un alto porcentaje (más del 50\%) de los artefactos líticos que han sido recuperados en los sitios arqueológicos fueron confeccionados sobre ftanita o chert. Esta situación es de suma importancia ya que evidencia estrategias diferentes a las empleadas en otras áreas de la región pampeana (p.e., área interserrana), en donde los porcentajes de cuarcitas son superiores a los de ftanita (Messineo 2002).

\section{Geología de las Sierras Bayas y caracterización de las ftanitas}

Las sierras septentrionales de la provincia de Buenos Aires (Harrington 1956) se extienden desde las lomadas de Quillalauquén con rumbo noroeste-sureste, hasta Mar del Plata por más de 300 $\mathrm{km}$. En las cercanías de Olavarría (10 km al sureste) se presentan unas elevaciones que han sido denominadas Sierras Bayas, las cuales abarcan 
$130 \mathrm{~km}^{2}$. Este núcleo orográfico comprende a varios cerros y lomas dispuestos en tres núcleos transversales al eje mayor (rumbo NNE-SSO): 1) Núcleo Septentrional, formado por los cerros Matilde, Largo, Aguirre y del Diablo; 2) Núcleo Central, representado por el cerro Tres Lomas y Redondo; y 3) Núcleo Austral, que corresponde a la Loma Negra y a los cerros Bayo y La Horqueta, con sus prolongaciones al sur y sursuroeste (González Bonorino 1954; Poiré e Iñíguez 1984).

Los estudios geológicos llevados a cabo en el núcleo septentrional de las Sierras Bayas (Poiré 1987, 1993) han podido comprobar la presencia de tres secuencias de depositación (cubierta sedimentaria), las cuales se corresponden con tres grandes ciclos sedimentarios no coetáneos. La cubierta sedimentaria se encuentra apoyada en discordancia sobre el basamento que tiene su parte superior alterada (Poiré 1987).

Como ya se ha mencionado, la ftanita aparece por lo menos en tres niveles estratigráficos dentro de la secuencia sedimentaria Precámbrica/Paleozoica inferior de las Sierras Bayas de Olavarría. El primer nivel de ftanita fue observado y definido en la cantera Amarilla, hallándose en los senos de los bioestromas dómicos basales en la primera secuencia sedimentaria o Formación Villa Mónica (Poiré 1987, 1993). El segundo nivel de ftanita se halla representado en la base de la segunda secuencia de depositación o Formación Cerro Largo. Este nivel es el que se halla aflorando en todos los cerros prospectados en el área y para los cuales se han hallado asociados canteras y talleres arqueológicos (Lozano 1991; Messineo 2001, 2002). El tercer nivel de ftanita se ubica en el contacto entre las Formaciones Loma Negra y Cerro Negro, constituyendo la base de esta última (Figura 3).

La brecha de ftanita se ubica generalmente como un banco entre las fangolitas. Su coloración es marrón rojiza a amarillenta y está dada por la matriz que, en general, se encuentra bien consolidada por silicificación. Los clastos son de colores grises oscuros a incoloros, tenaces, de bordes cortantes y se disponen caóticamente; su tamaño medio es de $9 \mathrm{~cm}$, alcanzando extremos tales como guijones de $25 \mathrm{~cm}$; son angulosos a muy angulosos. Microscópicamente se puede apreciar que los clastos están compuestos por calcedonia y cuarzo (Poiré e Iñíguez 1984). Estos autores mencionan que la ftanita o chert de las Sierras Bayas se presenta como una brecha que sobresale de los faldeos por su resistencia a la erosión y que la coloración de esta roca es muy variable (grises oscuros a incoloros, rojo, negro, verde, entre otros) (Poiré e Iñíguez 1984; Poiré 1987, 1993). Cabe destacar que, desde el punto de vista mineralógico, la ftanita se compone de tres minerales silíceos: cuarzo macro y microcristalino, calcedonia y ópalo. En general, se reconoce en la ftanita analizada en el área de Olavarría un predominio de cuarzo microcristalino sobre los otros dos componentes. La calcedonia tiene baja participación y el ópalo es sumamente escaso y sólo se lo ha reconocido ocasionalmente (Poiré et al. 2001). Por otro lado, la ftanita es químicamente inerte y mecánicamente resistente y dadas estas propiedades es que puede ser utilizada como indicador de proveniencia en base a sus características petrográficas (ópticas).

\section{Diferenciación entre los niveles de ftanita}

En un trabajo previo (Messineo et al. 2004) se realizó la identificación litológica del segundo y tercer nivel de ftanita con el fin de poder determinar sus similitudes y diferencias. Se recolectaron y estudiaron 12 muestras de rocas obtenidas de los dos niveles de ftanita. Nueve muestras fueron extraídas del segundo nivel, las cuales provenían de cerros distintos (Cerro Aguirre, Cerro Largo y Cerro Tres Lomas) y las tres muestras restantes correspondientes al tercer nivel se extrajeron de canteras actuales (Feitis y Avellaneda). Con respecto al primer nivel de ftanita, fue imposible obtener muestras ya que se encontraba bajo agua en una cantera actual.

Sobre las muestras obtenidas de los dos niveles, las cuales presentaban variación en el color y la textura, se realizó un estudio mineralógico de detalle, por medio del análisis petrográfico y de difracción de Rayos X, para establecer las características distintivas de estos materiales según el nivel del que proceden. Por un lado, los cortes delgados permitieron observar la estructura, los tamaños, los colores, la orientación, el modo de agregación de los minerales, entre otros. Por otro lado, la difracción de Rayos X permitió, mediante el análisis de Roca Total, reconocer todos aquellos componentes minerales presentes en la roca, que se encuentran en una proporción por lo general mayor al $3 \%$. 


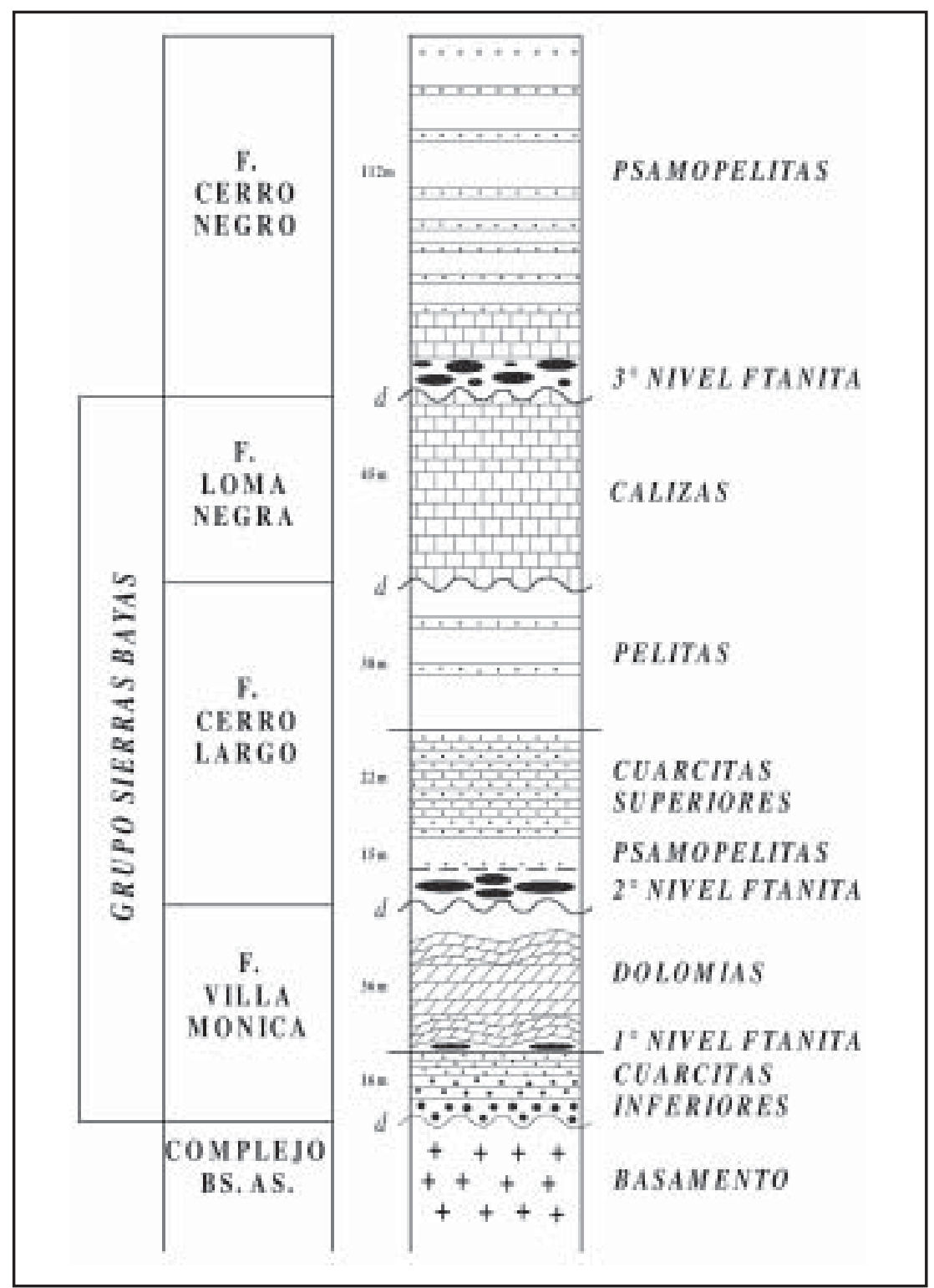

Figura 3. Esquema estratigráfico de las Sierras Bayas y ubicación de los distintos niveles de ftanita o chert. Tomado y modificado de Messineo y colaboradores (2004).

En los resultados obtenidos de los difractogramas correspondientes al segundo nivel de ftanita se observa un predominio de cuarzo (más del 95\%) y menores proporciones de calcedonia y ópalo (Figura 4). Por otro lado, en las tres muestras del tercer nivel se determinó la presencia de apatita y calcita, las cuales no fueron identificadas en las muestras del segundo nivel (Figura 5). En este sentido, como resultado de los análisis realizados pudimos observar diferencias en la composición mineralógica entre los dos niveles de ftanita.
Con respecto a los resultados obtenidos mediante los cortes delgados podemos mencionar que las muestras del segundo nivel de ftanita presentan una gran similitud en la estructura interna de la roca. En el corte petrográfico de la muestra 2 (Figura 6a) se puede observar la presencia de abundantes oolitos, el predominio de calcedonia tanto dentro como fuera de los oolitos, poros rellenos con cuarzo policristalino y venas de calcedonia que atraviesan la estructura interna de la roca, interpretándose a esta muestra como una caliza 


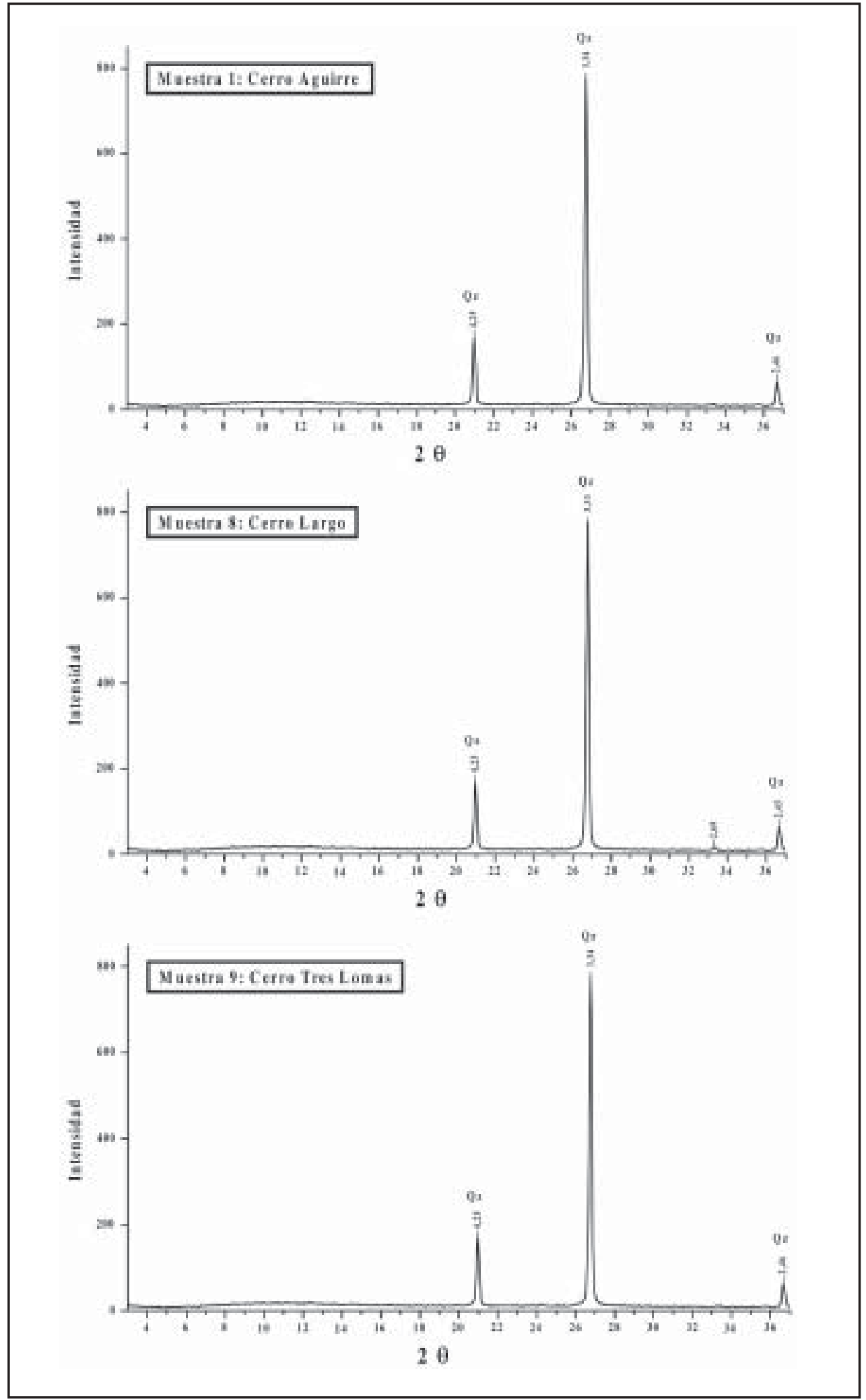

Figura 4. Resultados de la difracción de Rayos X sobre el segundo nivel de ftanita. Referencias: Qz: cuarzo. 


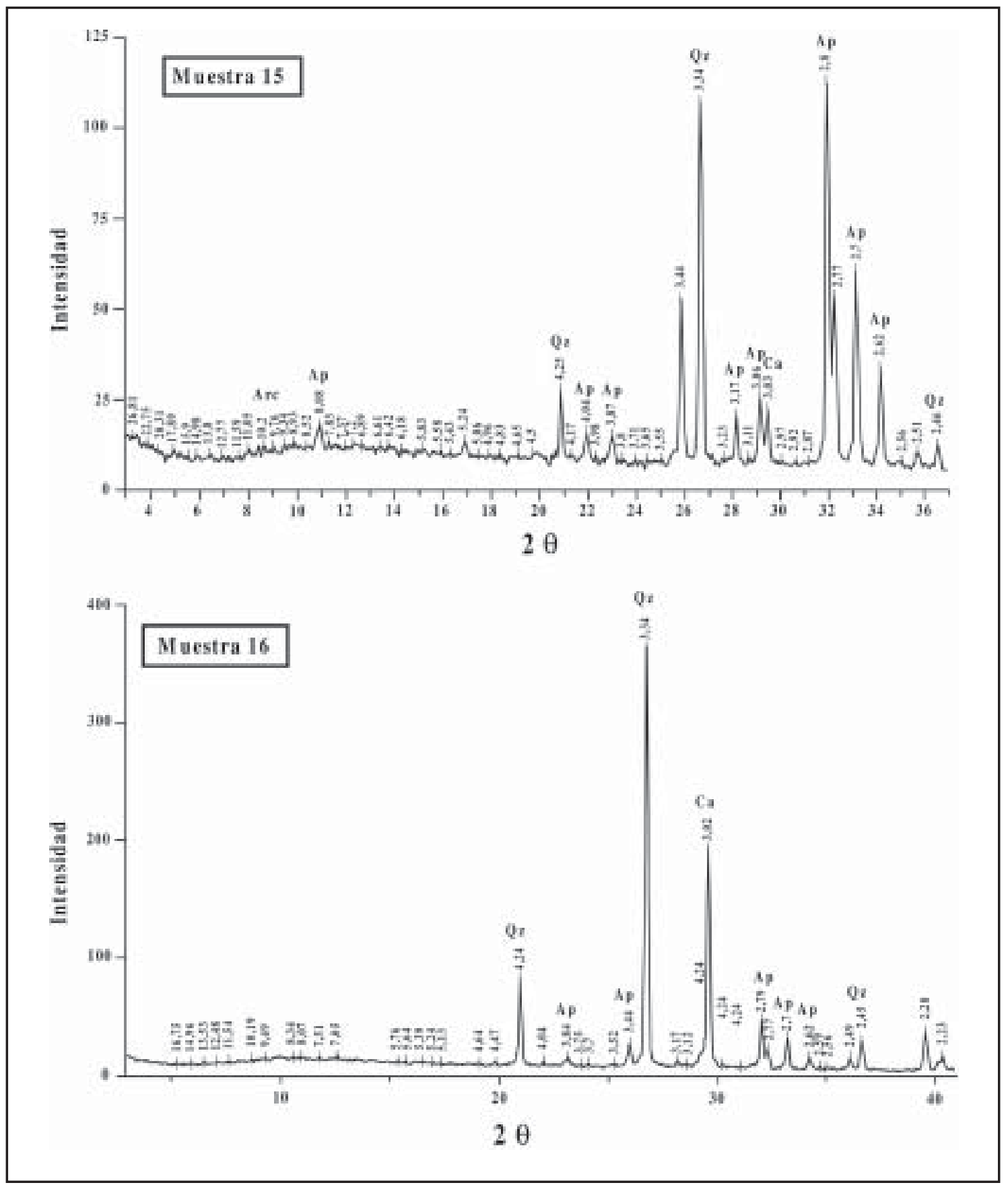

Figura 5. Resultados de la difracción de Rayos X sobre el tercer nivel de ftanita. Referencias: Qz: cuarzo; Arc: arcilla; Ap: apatita; Ca: calcita.

oolítica que fue reemplazada completamente por sílice en forma de chert.

Por otro lado, en las muestras del tercer nivel se observan variaciones respecto de las del segundo, las cuales se evidencian en la participación de minerales tales como calcita (como relleno de fracturas) y minerales de hierro. La muestra 16 (Figura 6b) presenta la siguiente composición mineralógica: calcita, cuarzo microcristalino, chert con predominio de calcedonia y apatita criptocristalina. 


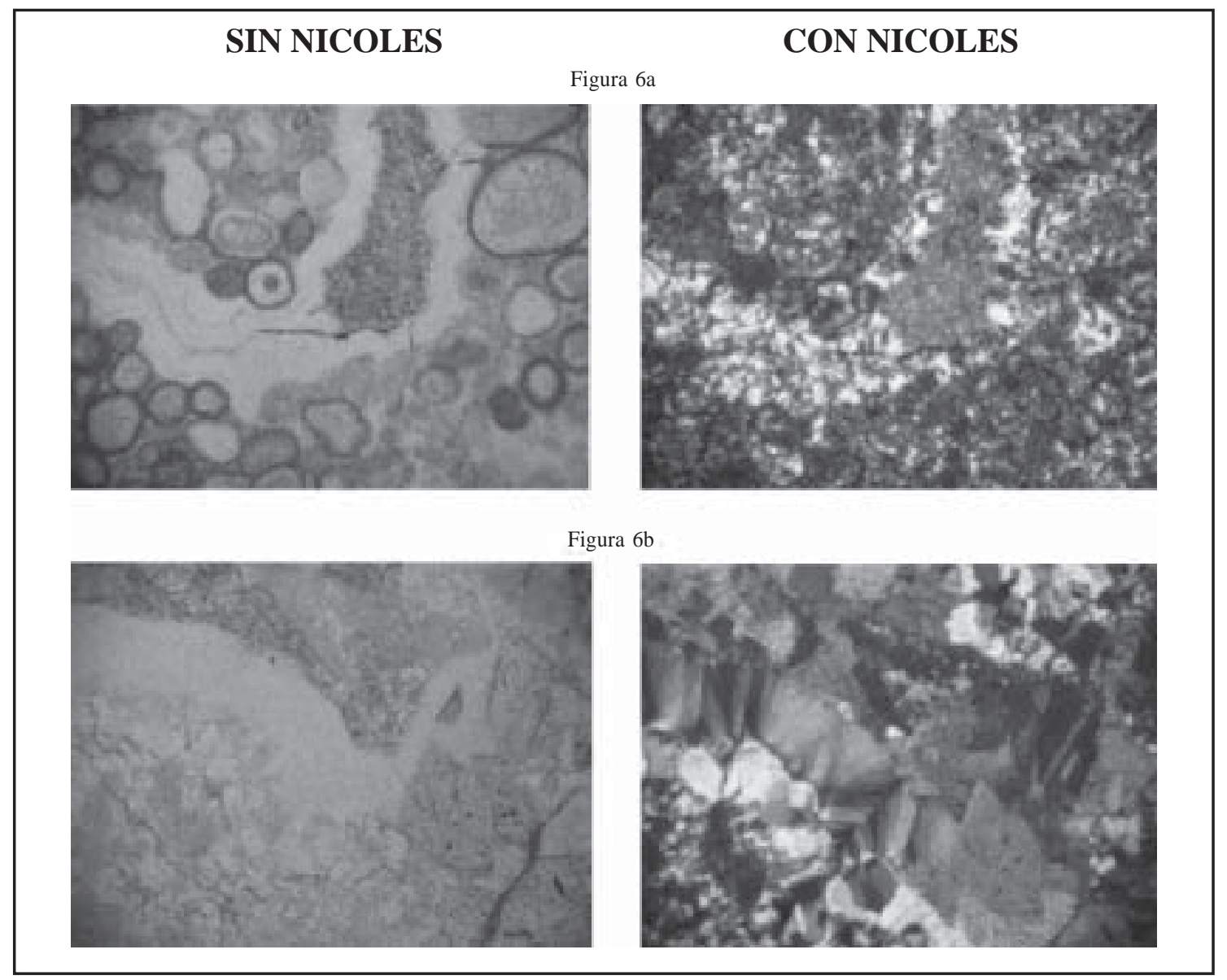

Figura 6. Cortes delgados realizados al segundo y tercera de ftanita de las Sierras Bayas: a) muestra proveniente del segundo nivel de ftanita; b) muestra proveniente del tercer nivel de ftanita.

Es importante destacar que las muestras del segundo nivel, provenientes de distintos cerros, presentaban macroscópicamente diferencias en el color y en la textura, y los resultados obtenidos mediante los análisis de difracción de Rayos X y petrografía no mostraron diferencias en la composición mineralógica. Por lo tanto, el color y la textura de las materias primas no son variables aptas para discriminar tipo de roca y procedencia de las mismas.

\section{Sitios arqueológicos considerados}

Como se mencionó anteriormente, uno de los objetivos de este trabajo era realizar una comparación de los niveles de ftanita reconocidos en las Sierras Bayas con los materiales provenientes de distintos sitios arqueológicos superficiales ubicados en la cuenca superior del Arroyo Tapalqué.
Los artefactos líticos de los sitios se encuentran en ambientes lagunares (Laguna La Barrancosa-2 y Blanca Chica), del sector serrano (Cerro Núcleo Central-1) y en sectores del Arroyo Tapalqué (p.e., Empalme Querandíes) (ver Figura 1).

\section{Laguna La Barrancosa-2}

La Laguna La Barrancosa-2 es un sitio superficial que se encuentra ubicado sobre una lomada en la parte sur de dicha laguna en el partido de Benito Juárez a los $37^{\circ} 21^{\prime}$ Latitud Sur y a los $60^{\circ} 06^{\prime}$ Longitud Oeste. Las prospecciones fueron desarrolladas durante los meses de marzo de 2002 y mayo de 2003. Se llevó a cabo una recolección superficial de materiales arqueológicos mediante el empleo de transectas y de una serie de sondeos o pruebas de pala para constatar la presencia de materiales en estratigrafía. 
La superficie del sitio es de aproximadamente $15000 \mathrm{~m}^{2}$.

Los materiales recuperados fueron principalmente en artefactos líticos. Dentro de los hallazgos podemos mencionar la presencia de varias puntas de proyectil triangulares pequeñas (en algunos casos fracturadas) y la presencia varios fragmentos de cerámica, lo que indicaría que el sitio se ubicaría cronológicamente en el Holoceno Tardío (ca. 3500-500 años AP).

Con respecto al material lítico se recuperaron 929 piezas, incluyendo desechos, instrumentos y núcleos. Los análisis realizados indican que la materia prima más representada es la ftanita con el $68.35 \%(\mathrm{n}=635)$, seguida por la cuarcita con el $25.94 \%(n=241)$ y el $5.71 \%$ restante $(n=53)$ corresponde a otras materias primas (p.e., dolomía silicificada, cuarzo, basalto, limolita silicificada y rocas indeterminables) (Tabla 1). Es importante destacar que el basalto provendría de rodados costeros y la limolita silicificada del sistema serrano de Ventania o de afloramientos ubicados en el área interserrana (Harrington 1980). Por otro lado, se observó la presencia de un instrumento confeccionado sobre un chert macroscópicamente diferente a la ftanita de las Sierras Bayas de Olavarría y cuya procedencia podrían ser los afloramientos registrados en la provincia de La Pampa (p.e., Meseta del Fresco y/o Laguna El Carancho) (Berón y Curtoni 2002).

\section{Laguna Blanca Chica}

La Laguna Blanca Chica se encuentra ubicada en el sector noroccidental de la cuenca superior del Arroyo Tapalqué, en el partido de Olavarría, a los $36^{\circ} 27^{\prime}$ de Latitud Sur y a los $60^{\circ} 27^{\prime}$ de Longitud Oeste (Messineo 2002). Las investigaciones en dicha laguna fueron realizadas por Lozano quien durante los años 1989/91 recolectó mate- riales superficiales y realizó sondeos en distintos sectores de la laguna, recuperando abundante material lítico, algunos restos óseos indeterminables y materiales actuales (vidrio y metal).

El total del material lítico recuperado suma 923 piezas, de las cuales 513 son de ftanita $(55.58 \%)$, 399 de cuarcita $(43.23 \%)$ y el resto $(n=11)$ corresponde a otras materias primas (dolomía silicificada e indeterminables) (1.19\%) (ver Tabla 1). Por otro lado, se determinó la presencia de 100 instrumentos (10.83\% del total), tanto formales (raspadores, raederas, entre otros) como informales (lascas con rastros de uso, entre otros) (sensu Andrefsky 1994), confeccionados mayoritariamente sobre ftanita (67\%) (Messineo y D'Augerot 2004).

\section{Cerro Núcleo Central-1}

El sitio Cerro Núcleo Central-1 se encuentra ubicado en el sector serrano de las Sierras Bayas en el partido de Olavarría a los $36^{\circ} 50^{\prime}$ de Latitud Sur y a los $60^{\circ} 11^{\prime}$ de Longitud Oeste. Las prospecciones en el lugar se efectuaron en los años 2001 y 2002. El material arqueológico se hallaba en superficie producto de la construcción de un camino que accedía a una de las canteras de extracción de arcillas. Para realizar la recolección de los mismos se efectuó la división del sitio en transectas de $2 \mathrm{~m}$ de ancho cada una, ubicadas transversalmente al camino.

Los materiales arqueológicos recuperados fueron únicamente de 558 artefactos líticos, de los cuales 500 eran de ftanita $(89.61 \%), 56$ de cuarcita $(10.03 \%)$ y dos de otras materias primas $(0.36 \%)$ (ver Tabla 1). Dentro del material analizado se hallaron 66 nódulos, de los cuales 52 son de ftanita y el resto $(n=14)$ de cuarcita, siendo estos últimos de mala calidad para la talla. Además, se recuperaron 23 núcleos de ftanita $(4.12 \%$ del total), no

\begin{tabular}{|l|c|c|c|c|c|c|c|c|}
\hline \multirow{2}{*}{ Sitios } & \multicolumn{2}{|c|}{ Ftanita } & \multicolumn{2}{c|}{ Cuarcita } & \multicolumn{2}{c|}{ Otras } & \multicolumn{2}{c|}{ Total } \\
\cline { 2 - 9 } & $\mathbf{N}$ & \% & N & \% & N & \% & N & \% \\
\hline Laguna La Barrancosa-2 & 635 & 68.35 & 241 & 25.94 & 53 & 5.71 & 929 & 100 \\
Laguna Blanca Chica & 513 & 55.58 & 399 & 43.23 & 11 & 1.19 & 923 & 100 \\
Cerro Núcleo Central-1 & 500 & 89.61 & 56 & 10.03 & 2 & 0.36 & 558 & 100 \\
Arroyo Tapalqué & 141 & 56.85 & 102 & 41.13 & 5 & 2.02 & 248 & 100 \\
\hline
\end{tabular}

Tabla 1. Porcentaje de las materias primas líticas presentes en los sitios arqueológicos. 
registrándose la presencia de núcleos confeccionados sobre cuarcita. Por otro lado, las lascas y los desechos de talla son en su mayoría de ftanita $(n=418: 91.07 \%)$ y se hallaron bajos porcentajes de cuarcita $(n=41: 8.93 \%)$. Solamente se recuperaron ocho instrumentos, de los cuales siete son de ftanita $(87.5 \%)$ y uno de cuarcita $(12.5 \%)$.

Los datos preliminares que se han obtenido en el sitio Cerro Núcleo Central-1 indicarían que éste pudo haber funcionado como un taller de ftanita, en donde se llevaron a cabo las primeras etapas de la reducción lítica. Este taller es un registro importante ya que en el área se ha señalado la presencia de canteras potenciales de explotación, canteras-taller y talleres sobre esta materia prima, los cuales se ubican en las laderas de los distintos cerros que conforman las Sierras Bayas (Lozano 1991; Messineo 2001, 2002).

\section{Arroyo Tapalqué}

Las prospecciones en el Arroyo Tapalqué fueron realizadas desde el Empalme Querandíes hasta el casco urbano de la ciudad de Olavarría, recuperándose materiales líticos en superficie y en estratigrafía, y registrándose la presencia de varios sitios arqueológicos (p.e., Empalme Querandíes, Paso de la India), los cuales hasta el momento no han sido excavados. Por otro lado, se analizaron materiales que se hallan depositados en el Museo "Dámaso Arce" de Olavarría, los cuales provienen de distintos sectores del Arroyo Tapalqué.

Dentro del material lítico recuperado $(\mathrm{n}=248)$, se constató que el $56.85 \%(\mathrm{n}=141)$ correspondía a ftanita, el $41.13 \%(n=102)$ a cuarcita y el $2.02 \%$ $(n=5)$ a otras materias primas (ver Tabla 1). Además, se registró la presencia de 35 instrumentos ( $14.11 \%$ del total), de los cuales 22 son de ftanita (62.86\%), 12 de cuarcita (34.28\%) y uno de granito $(2.86 \%)$. Por otro lado, se hallaron 22 núcleos $(8.87 \%$ del total), siendo 15 de ftanita $(68.18 \%)$ y siete de cuarcita $(31.82 \%)$.

Como se puede observar de los resultados obtenidos, la materia prima más representada tanto para instrumentos, núcleos y desechos de talla corresponde a la ftanita, mientras que la cuarcita se halla en menores porcentajes, situación similar a la registrada en los otros sitios ubicados en la cuenca superior del Arroyo Tapalqué.

\section{Muestras seleccionadas y resultados obtenidos}

Se seleccionaron tres muestras de cada uno los sitios o localidades arqueológicas arriba consideradas, tratando de obtener la mayor variabilidad, tanto en el color como en la textura de las rocas. Los colores (según la escala de Munsell) van desde negras, grises, grises claros, rojas, gris verdoso y traslúcidas.

Los difractogramas de las muestras de la totalidad de los sitios arqueológicos evidencian como elemento principal al cuarzo (95\%), estando representados en menores proporciones calcedonia y ópalo (Figura 7). Los resultados obtenidos están indicando que los porcentajes de las muestras arqueológicas son similares a los obtenidos para las muestras del segundo nivel de ftanita o chert proveniente de la Sierras Bayas (ver Figura 4; también ver Messineo et al. 2004, fig. 3). Por otro lado, en las muestras arqueológicas no se registró la presencia de minerales como la apatita y la calcita, los cuales están presentes en el tercer nivel de ftanita de las Sierras Bayas.

En un trabajo previo (Messineo et al. 2004) se propuso como hipótesis que los grupos humanos habrían explotado principalmente el segundo nivel de chert o ftanita. Los resultados obtenidos corroboran e indican claramente la similitud en cuanto a las características litológicas del segundo nivel de ftanita con las muestras arqueológicas.

\section{Discusión y conclusiones}

Los grupos humanos en la zona de la cuenca superior del Arroyo Tapalqué han trabajado una gran variedad de materiales líticos, rocas esencialmente de origen sedimentario, aunque también existe la explotación de algunos minerales (p.e., cuarzo y pigmentos). Las rocas talladas están ligadas al contexto geológico del cual fueron extraídas y su elección está determinada, en parte, por las instalaciones y los desplazamientos de los grupos cazadores-recolectores (Inizan et al. 1995; Ericson 1984). En este trabajo intentamos, por medio de los análisis de difracción de Rayos X, determinar la procedencia de la ftanita encontrada en cuatro sitios arqueológicos que se ubican en la cuenca superior del Arroyo Tapalqué y discutir el uso de esta materia prima, tanto en la cuenca como en sectores cercanos a la misma. 


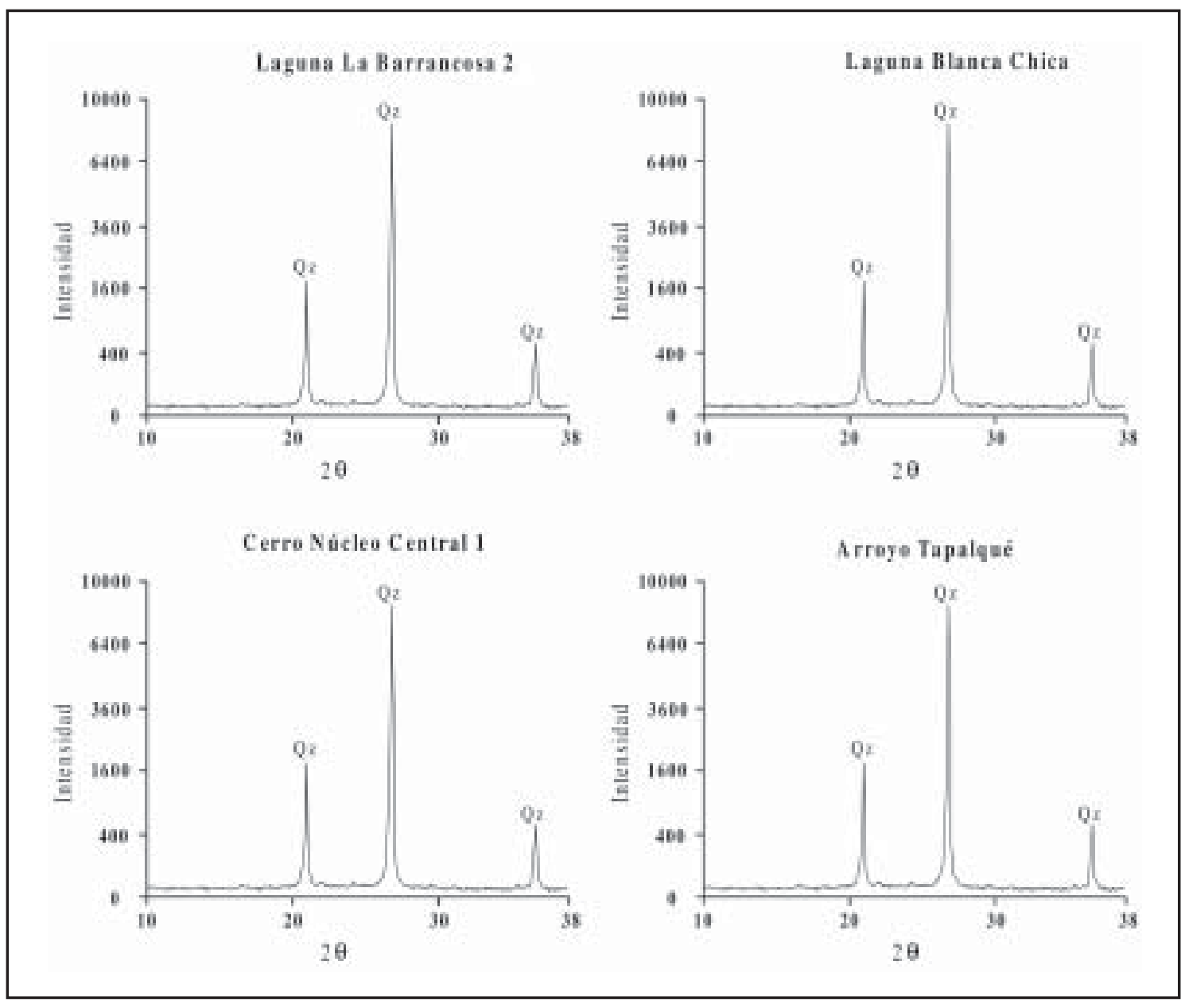

Figura 7. Resultados de la difracción de Rayos X sobre las muestras de los sitios arqueológicos. Referencias: Qz: cuarzo.

Como se puede observar, los resultados obtenidos de las muestras de ftanita de los sitios arqueológicos ubicados en la cuenca superior del Arroyo Tapalqué están mostrando similitudes con el segundo nivel de ftanita registrado en las Sierras Bayas. Esta similitud se evidencia en la presencia del $95 \%$ de cuarzo y, en menores proporciones, otros minerales como la calcedonia. Por otro lado, se observó que las muestras no presentaban calcita y apatita, lo que permite diferenciar a las muestras arqueológicas del tercer nivel de ftanita (ver composiciones en Figuras 4, 5 y 7).

Calculamos las distancias de los sitios considerados en este trabajo a las fuentes de ftanita provenientes del segundo nivel reconocidas en las Sierras Bayas. Sólo se utilizaron las canteras y talleres arqueológicamente determinados y no utiliza- mos las fuentes potenciales. Las fuentes consideradas fueron Cerro Aguirre, Cerro Largo, Cerro Tres Lomas y el sitio taller Cerro Núcleo Central-1.

La distribución de esta materia prima muestra que los sitios arqueológicos se encuentran a distancias diferentes a las fuentes, aunque las mismas no superan los $50 \mathrm{~km}$. El sitio Laguna Blanca Chica se encuentra aproximadamente a $28 \mathrm{~km}$ de las fuentes de ftanita y los materiales recuperados en el Arroyo Tapalqué, tomado desde el Empalme Querandíes, se halla a una distancia promedio de $19.61 \mathrm{~km}$ de las canteras-talleres relevadas en las sierras. Por otro lado, la distancia del sitio Laguna La Barrancosa-2 a las fuentes de ftanita detectadas en las Sierras Bayas es en promedio de $44.91 \mathrm{~km}$, siendo el sitio que se halla a mayor distancia (ver distancias mínimas y máximas en Tabla 2). 


\begin{tabular}{|lllc|}
\hline Sitios & Distancia a las canteras y talleres & Km & Promedio en km \\
\hline Laguna Blanca Chica & Al Cerro Aguirre & 30.79 & 28.81 \\
& Al Cerro Tres Lomas & 26.66 & \\
& Al Cerro Largo & 29.28 & \\
& Al Cerro Núcleo Central 1 & 28.51 & 44.91 \\
Laguna La Barrancosa 2 & Al Cerro Aguirre & 46.35 & \\
& Al Cerro Tres Lomas & 43.07 & 19.61 \\
& Al Cerro Largo & 47.79 & \\
Empalme Querandíes & Al Cerro Núcleo Central 1 & 42.46 & \\
& Al Cerro Aguirre & 23.02 & 15.38 \\
\end{tabular}

Tabla 2. Distancia en km de los sitios arqueológicos a las canteras-taller pertenecientes al segundo nivel de ftanita registradas en las Sierras Bayas.

Es importante destacar que otras fuentes de ftanita (tanto explotadas como potenciales) han sido reconocidas en varios sectores del Sistema Serrano de Tandilia. Entre las fuentes que han sido explotadas podemos mencionar el sector del Arroyo Diamante, ubicado en la proximidad de la localidad de Barker (Flegenheimer et al. 1996). Según los estudios geológicos esta materia prima se encontraría en un nivel estratigráfico diferente al establecido para el segundo nivel de ftanita reconocido en las Sierras Bayas, ya que el mismo se ubicaría por encima de las cuarcitas correspondientes al Miembro superior de la Formación Sierras Bayas y suprayacentes a las cuarcitas de la Formación Balcarce (Manassero 1986). En este sector se localizaron dos afloramientos de ftanita (también denominada sílice microcristalina), de los cuales uno se localiza próximo a las canteras de cuarcita y presenta evidencia de haber sido explotado (Flegenheimer et al. 1996).

Entre las fuentes potenciales podemos mencionar dos sectores diferentes, por un lado, un conglomerado que constituye una fuente primaria de ftanita localizado en el Cerro El Sombrero en el partido de Lobería, el cual está ubicado en la base de las ortocuarcitas de la Formación Balcarce y apoyando sobre el basamento igneometamórfico (Barna y Kain 1994). Por otro lado, nosotros observamos en las proximidades de Chillar (Cerro San Lorenzo) nódulos de ftanita de dimensiones pequeñas, los cuales pueden corresponder a depósitos secundarios. Es importante destacar que este sector se encuentra en gran parte cubierto de sedimento y sólo se pueden observar los mate- riales líticos cuando los campos son arados. Si tenemos en consideración la fuente de ftanita potencial ubicada en Chillar, las distancias del sitio Laguna La Barrancosa-2 serían de aproximadamente de $10 \mathrm{~km}$.

Nuestro segundo objetivo era determinar las estrategias de obtención y explotación de la ftanita en la cuenca superior del Arroyo Tapalqué y sectores próximos. Para ello utilizamos dos variables fundamentales: la espacial y la temporal. Por un lado, la identificación de las materias primas y la localización de las fuentes se refleja en la dimensión espacial, es decir, puede ser tomada como una medida del traslado de la roca en el paisaje y se puede medir la distancia que esa materia prima ha sido transportada. El análisis de procedencia permite determinar el contacto entre dos o más localidades geográficas: la fuente geológica y los sitios arqueológicos (Luedtke 1978; Escola et al. 1998).

Por otro lado, la variable temporal nos puede mostrar los cambios en la utilización de los distintos tipos de materias primas a través del tiempo en un área o región determinada. Es decir, si consideramos que el acceso a los recursos líticos y el conocimiento de los grupos es constante (Geneste 1988), las diferencias que se encuentren en el registro arqueológico a través del tiempo pueden estar indicando el uso de diferentes estrategias tecnológicas vinculadas con la obtención, manejo y utilización de las materias primas líticas. Sin embargo, los sitios analizados aquí se ubicarían cronológicamente en el Holoceno Tardío. 
Como mencionamos anteriormente, la ftanita ha sido considerada según su explotación de forma mayoritariamente local y, en menor medida, de forma areal y regional y asociada con la producción de instrumentos formales (Lozano 1991; Flegenheimer y Bayón 2002). Sin embargo, los resultados obtenidos en nuestras investigaciones en la cuenca superior del Arroyo Tapalqué y los datos generados por otros investigadores en sectores próximos, muestran que la ftanita ha tenido una explotación y uso mucho más importante en el sector noroccidental del área interserrana (partidos de General Lamadrid y Laprida), en el sector occidental del Sistema Serrano de Tandilia (partidos de Olavarría y Benito Juárez) y en el sector oriental del Area Oeste (partidos de Tapalqué y Bolívar). Los porcentajes de ftanita en los sitios considerados, tales como Laguna La Barrancosa-2 (68.35\%), Laguna Blanca Chica (55.58\%) y Empalme Querandíes (56.85\%), ubicados en la cuenca superior del Arroyo Tapalqué, son superiores con respecto a las cuarcitas y a otras materias primas.

Por otro lado, los trabajos de Bórmida (1960, s/f) en las lagunas ubicadas principalmente en los partidos de Bolívar y Olavarría muestran que un alto porcentaje de los instrumentos fueron confeccionados sobre ftanita. Por ejemplo, el sitio Laguna Cabeza de Buey presenta el $51.02 \%$ de instrumentos confeccionados sobre ftanita, Laguna El Recado el 46.43\%, Laguna Cubiló el 44.45\% y la Laguna Blanca Grande el 35.05\%. Es importante destacar que las investigaciones de Bórmida se centraron únicamente en el análisis de instrumentos, desechándose el resto de los materiales líticos (p.e., desechos) recuperados en los sitios arqueológicos.

Como producto de las investigaciones realizadas por Crivelli Montero y colaboradores (1990/92), se detectaron varios sitios arqueológicos en el partido de Tapalqué (p.e., Laguna Medina, Laguna Pluma Augero). Aunque los materiales líticos recuperados en dichas lagunas no eran abundantes, presentaban en algunos casos porcentajes de ftanita superiores a otras materias primas, y en otros casos, la cuarcita estaba mayoritariamente representada aunque se observaban altos porcentajes de ftanita.

Otras investigaciones cerca de la cuenca en los partidos de General Lamadrid y Laprida fueron realizadas por Crivelli Montero y colaboradores (1997). Varios de los sitios trabajados por este equipo muestran que la materia prima lítica más representada es la cuarcita, aunque la ftanita está representada en porcentajes más altos que otros sitios que se encuentran en el área interserrana. Por ejemplo, el sitio Fortín Necochea presenta entre un $25 \%$ y $30 \%$ de ftanita en su contexto, Laguna del Trompa un $25 \%$ y Escuela Agropecuaria un $40 \%$.

Es importante destacar que el sitio superficial Escuela Agropecuaria, ubicado en el sector norte del partido de General Lamadrid, es el que se localiza más cerca de la cuenca superior del Arroyo Tapalqué y el que presenta en su contexto aproximadamente un $40 \%$ de ftanita (Crivelli Montero et al. 1997).

Un aspecto que debe ser investigado con mayor profundidad es la variable temporal, ya que todos los sitios ubicados en la cuenca del Arroyo Tapalqué provienen de contextos superficiales, lo cual dificulta acceder a un marco contextual y cronológico. Sin embargo, es importante destacar que la muestra del sitio Laguna La Barrancosa-2 presenta ciertas características tecnológicas que la podrían ubicar en el Holoceno Tardío, como son las puntas de proyectil triangulares pequeñas y la presencia de cerámica. Sobre la base de estos datos se piensa que gran parte de los materiales arqueológicos del sitio podrían corresponder también a este momento; sin embargo, se necesitan contextos estratigráficos y más estudios tecnológicos en detalle sobre los materiales que se han hallado.

A partir de los resultados obtenidos en las investigaciones de los últimos años, se pueden plantear diferentes estrategias tecnológicas con respecto al uso de la ftanita. Por un lado, la tendencia general de los análisis efectuados en el sitio Núcleo Central-1 nos muestra que la elección de los nódulos de ftanita estuvo en relación con la morfología natural de los mismos, debido a que gran parte de ellos posee una o dos superficies planas, las cuales fueron utilizadas como plataforma de percusión en la etapa de producción. La producción está orientada a la obtención de lascas de distintos tipos, siendo la técnica empleada la percusión directa dura y blanda. Varias lascas fueron utilizadas naturalmente, mientras que otras fueron transformadas mediante el retoque por percusión y presión. 
Por otro lado, en los sitios Laguna Blanca Chica y Laguna La Barrancosa-2 se observó que los instrumentos tanto formales como informales fueron confeccionados mayoritariamente sobre ftanita, lo cual puede relacionarse con la gran disponibilidad y excelente calidad de esta materia prima para la talla (Messineo y D'Augerot 2004). La presencia de instrumentos informales y de lascas de filos naturales con rastros de utilización en los sitios ubicados próximos a las fuentes está evidenciando una explotación diferencial a la postulada por Lozano (1991), la cual planteaba sólo la utilización de una tecnología conservada sobre esta materia prima en la región pampeana.

Por último, los sitios superficiales del Holoceno Tardío que poseen mayor porcentaje de ftanita en la cuenca superior del Arroyo Tapalqué (p.e., Laguna La Barrancosa-2) se encuentran ubicados a menos de $50 \mathrm{~km}$ de las fuentes de abastecimiento. Esta mayor utilización de la materia prima local estaría avalando lo planteado por otros investigadores que mencionan que durante el Holoceno Tardío los grupos cazadores recolectores que habitaron la región pampeana realizaron una ocupación efectiva del espacio regional, disminuyendo su rango de movilidad y planteando la existencia de comportamientos territoriales (Barrientos 1997; Martínez 1999; Madrid y Barrientos 2000; Politis y Madrid 2001).

Sin embargo, insistimos en que más investigaciones deben ser realizadas en sitios con estratigrafía, ya que un tema que todavía debemos evaluar es la variable temporal y si los comportamientos de los grupos humanos en el pasado fueron variando a través del tiempo.

Agradecimientos A Daniel Poiré y a Lucía Gómez Peral por la ayuda brindada en la interpretación de los cortes delgados y de difracción de Rayos X de los niveles de ftanita. A Viviana Bonaveti y Fabián Irazar por la realización de la difracción de Rayos X de las muestras de los sitios arqueológicos. A Patricia Madrid, Gustavo Martínez y Patricia Escola por la lectura y sugerencias brindadas a este trabajo. A Cristian Kaufmann por ayudarnos en la realización de los gráficos. Esta investigación fue realizada con becas de investigación otorgadas por el Consejo Nacional de Investig aciones Científicas y Técnicas.

\section{REFERENCIAS CITADAS}

ANDREFSKY, W., 1994. Raw-material availability and the organization of technology. American Antiquity 59 (1): $21-34$

BARNA, A. y S. KAIN, 1994. Una fuente potencial de aprovisionamiento lítico en el cerro El Sombrero. Partido de Lobería (provincia de Buenos Aires). Revista del Museo de Historia Natural de San Rafael, T. XIV (1/4): 206-208.

BARRIENTOS, G., 1997. Nutrición y dieta de las poblaciones aborígenes prehispánicas del sudeste de la Región Pampeana. Tesis doctoral inédita. Facultad de Ciencias Naturales y Museo, Universidad de La Plata, La Plata.

BAYON, C. y C. ZAVALA, 1997. Coastal sites in south Buenos Aires: A review of Piedras Quebradas. En Quaternary of South America and Antarctic Peninsula, vol. 10 (1994), J. Rabassa y M. Salemme (Eds.), pp. 229-253. A. A. Balkema, Rotterdam, Bookfield.

BAYON, C., N. FLEGENHEIMER, M. VALENTE y A. PUPIO, 1999. Dime cómo eres y te diré de dónde vienes: La procedencia de rocas cuarcíticas en la región pampeana. Relaciones de la Sociedad Argentina de Antropología 24: 187-235.
BERON, M. y R. CURTONI, 2002. Propuesta metodológica para la caracterización arqueológica de canteras y talleres de la Meseta del Fresco (La Pampa, Argentina). En Del mar a los salitrales. Diez mil años de historia pampeana en el umbral del tercer milenio, D. Mazzanti, M. Berón y F. Oliva (Eds.), pp. 171-184. Universidad Nacional de Mar del Plata, Mar del Plata.

BERON, M., L. MIGALE y R. CURTONI, 1995. Hacia la definición de una base regional de recursos líticos en el área del Curacó. Una cantera taller: Puesto Córdoba (La Pampa, Argentina). Relaciones de la Sociedad Argentina de Antropología 20: 111-128.

BORMIDA, M., 1960. Investigaciones paleoetnológicas en la región de Bolívar, provincia de Buenos Aires. Anales de la Comisión de Investigaciones Científicas de la Provincia de Buenos Aires 1: 190-283.

- s/f. Prolegómenos para una arqueología de la Pampa Bonaerense. Edición oficial de la provincia de Buenos Aires, Dirección de Bibliotecas, Museos y Archivos Históricos, La Plata.

CRIVELLI MONTERO, E., M. FERNANDEZ, N. FRANCO, U. PARDIÑAS y Z. TAVELLA, 1990/1992. Pros- 
pecciones arqueológicas en el partido de Tapalqué (provincia de Buenos Aires). Paleoetnológica 6: 31-46.

CRIVELLI MONTERO, E., E. EUGENIO, U. PARDIÑAS y M. SILVEIRA, 1997. Archaeological investigation in the plains of the province of Buenos Aires, Llanura Interserrana Bonaerense. En Quaternary of South American and Antarctic Peninsula, vol. 10 (1994), J. Rabassa y M. Salemme (Eds.), pp. 167-209. A. A. Balkema, Rotterdam, Bookfield.

ERICSON, J., 1984. Toward the analysis of lithic production systems. En Prehistoric quarries and lithic production, J. Ericson y B. Purdy (Eds.), pp. 1-9. Cambridge University Press, Cambridge.

ESCOLA, P., C. VAZQUEZ y F. MOMO, 1998. Análisis de procedencia de artefactos de obsidiana: Vías metodológicas de acercamiento al intercambio. Revista del Museo de Historia Natural de San Rafael T. XX (1/4): 139-142.

FIDALGO, F., R. O. GENTILE y H. A. CORREA, 1986. Geología y geomorfología en la cuenca del Arroyo Tapalqué. Informe 30, CIC, La Plata.

FLEGENHEIMER, N., 1991. La Liebre, un sitio cantera-taller. Boletín del Centro 2: 58-64.

FLEGENHEIMER, N. y C. BAYON, 2002. Cómo, cuándo y dónde. Estrategias de abastecimiento lítico en la Pampa Bonaerense. Del mar a los salitrales. Diez mil años de historia pampeana en el umbral del tercer milenio, D. Mazzanti, M. Berón y F. Oliva (Eds.), pp. 231-241. Universidad Nacional de Mar del Plata, Mar del Plata.

FLEGENHEIMER, N., C. KAIN, M. ZARATE y A. BARNA, 1996. Aprovisionamiento de cuarcitas en Tandilia, las canteras de Arroyo Diamante. Arqueología 6: 117-141.

FLEGENHEIMER, N., M. ZARATE y M. VALENTE, 1999. El área de canteras Arroyo Diamante, Barker, Sierras de Tandil. Actas del XII Cong reso Nacional de Arqueología Argentina, pp. 134-138. La Plata.

GENESTE, J. M., 1988. Systèmes d'approvisionnement en matières premières au Paléolithique Moyen et au Paléolithique supérieur en Aquitaine. En L'Homme de Neandertal, vol. 8, La Mutation, pp. 61-70. Service de Préhistoire, Université de Liége, Liége.

GONZALEZ BONORINO, F., 1954. Geología de las Sierras Bayas, partido de Olavarría, provincia de Buenos Aires. LEMIT, Serie 2 (55): 5-37.

HARRINGTON, H., 1956. Argentina. Handbook of South American Geology. Geology Soc. American, W. F. Jenks (Ed.), Memoir 65: 129-165. Nueva York.

-1980. Sierras australes de la provincia de Buenos Aires. Segundo Simposio de Geología Regional Argentina, vol. 2: 967-983. Academia Nacional de Ciencias de Córdoba, Córdoba.
INIZAN, M., M. REDURON-BALLINGER, H. ROCHE y J. TIXIER, 1995. Technologie de la pierre taillée 4. Meudon: CREP Centre National de la Recherche Scientifique et de l'Université de Paris X, Nanterre.

IÑIGUEZ, A., A. DEL VALLE, D. POIRE, L. SPALLETTI y P. ZALBA, 1989. Cuenca precámbrica/paleozoica inferior de Tandilia, provincia de Buenos Aires. En Cuencas sedimentarias argentinas, G. Chebli y L. A. Spalletti (Eds.), Serie de Correlación Geológica 6: 245-263 Instituto Superior Correlación Geología, Universidad Nacional de Tucumán, Tucumán.

IÑIGUEZ, A., M. MANASSERO, D. POIRE y J. MAGGI, 1996. Génesis y procedencia de sedimentitas cuarzosas del área de Olavarría, provincia de Buenos Aires, Argentina. Actas VI Reunión de Sedimentología, pp. 61-66. Bahía Blanca.

LOZANO, P., 1991. Cerro Aguirre: Un sitio de aprovisionamiento de materia prima lítica en la localidad de Sierras Bayas (provincia de Buenos Aires). Shincal 3 145-150.

LUEDTKE, B., 1978. Chert sources and trace-element analysis. American Antiquity 43 (3): 413-423.

MADRID, P. y G. BARRIENTOS, 2000. La estructura del registro arqueológ ico del sitio Laguna Tres Reyes-1 (provincia de Buenos Aires): Nuevos datos para la interpretación del poblamiento humano del sudeste de la región pampeana a inicios del Holoceno Tardío. Relaciones de la Sociedad Argentina de Antropología 25: 179-206.

MANASSERO, M. J., 1986. Estratigrafía y estructura en el sector oriental de la localidad de Barker, provincia de Buenos Aires. Revista de la Asociación Geológica Argentina XLI (3-4): 375-385.

MARTINEZ, G., 1999. Tecnología, subsistencia y asentamiento en el curso medio del río Quequén Grande: Un enfoque arqueológico. Tesis doctoral inédita. Facultad de Ciencias Naturales y Museo, Universidad de La Plata, La Plata.

MESSINEO, P., 2001. Utilización de materias primas líticas en la cuenca superior del Arroyo Tapalqué (partido de Olavarría, provincia de Buenos Aires). Resúmenes del XIV Congreso Nacional de Arqueología Argentina, p. 63. Rosario.

2002. Primeros resultados arqueológicos en la cuenca del Arroyo Tapalqué (partido de Olavarría, provincia de Buenos Aires). En Del mar a los salitrales. Diez mil años de historia pampeana en el umbral del tercer milenio, D. Mazzanti, M. Berón y F. Oliva (Eds.), pp. 301-309. Universidad Nacional de Mar del Plata, Mar del Plata.

MESSINEO, P. y L. D'AUGEROT, 2004. Análisis preliminar de los materiales líticos provenientes de la Laguna Blanca Chica (Olavarría, Buenos Aires). Intersecciones en Antropología 5. En prensa.

MESSINEO, P., P. BARROS, D. POIRE y L. GOMEZ PERAL, 2004. Características litológicas de los niveles de chert o ftanitas en las Sierras Bayas (partido de Olavarría, 
provincia de Buenos Aires). En Aproximaciones contemporáneas a la arqueología pampeana. Perspectivas teóricas, metodológicas, analíticas y casos de estudio, G. Martínez, M. Gutiérrez, R. Curtoni, M. Berón y P. Madrid (Eds.). En prensa.

NAGERA, J., 1940. Historia física de la provincia de Buenos Aires, 1. Tandilia. Universidad Nacional de La Plata, Facultad de Humanidades y Ciencias de la Educación, Biblioteca Humanidades 24, La Plata.

OLIVA, F. y J. MOIRANO, 1997. Primer informe sobre aprovisionamiento primario de riolita en Sierra de la Ventana (provincia de Buenos Aires, Argentina). En Arqueología pampeana en la década de los '90, M. Berón y G. Politis (Eds.), pp. 137-146. Museo de Historia Natural de San Rafael - Investig aciones Arqueológicas y Paleontológicas del Cuaternario (INCUAPA) - Universidad Nacional del Centro de la Provincia de Buenos Aires, Mendoza.

ORMAZABAL, P., 1999. Lumb: Un sitio de aprovisionamiento de materia prima lítica para elementos de molienda. Actas del XII Congreso de Arqueología Argentina, pp. 156-164. La Plata.

POIRE, D. G., 1987. Mineralogía y sedimentología de la Formación Sierras Bayas en el núcleo septentrional de las sierras homónimas. Olavarría, provincia de Buenos
Aires. Tesis doctoral inédita. Facultad de Ciencias Naturales y Museo, Universidad Nacional de La Plata, La Plata.

_ 1993. Estratigrafía del Precámbrico sedimentario de Olavarría, Sierras Bayas, provincia de Buenos Aires, Argentina. Actas XII Congreso Geológico Argentino y II Congreso de Exploración de Hidrocarburos, T. 2: 1-11. Mendoza.

POIRE, D. G. y A. IÑIGUEZ, 1984. Miembro Psamopelitas de la Formación Sierras Bayas, partido de Olavarría, provincia de Buenos Aires. Revista de la Asociación Geológica Argentina XXXIX (3-4): 276-283.

POIRE, D. G., L. GOMEZ PERAL y J. M. CANALICCHIO, 2001. Estudio mineralógico del ópalo y chert en calizas a utilizar como agregado de hormigón, Precámbrico de Olavarría, provincia de Buenos Aires. Actas VII Congreso Argentino de Geología Económica, T. 2: 123-128. Salta.

POLITIS, G. y P. MADRID, 2001. Arqueología pampeana: Estado actual y perspectivas. En Historia argentina prehispánica, E. Berberián y A. Nielsen (Eds.), T. II: 737-813. Editorial Brujas, Córdoba.

PUPIO, A., 1996. Resultados preliminares del sitio canterataller La Liebre. Jornadas Chivilcoyanas en Ciencias Sociales y Naturales, pp. 191-194. Chivilcoy. 